\title{
Piper betle leaf extract enhances the cytotoxicity effect of 5-fluorouracil in inhibiting the growth of HT29 and HCT116 colon cancer cells*
}

\author{
Pek Leng NG ${ }^{1}$, Nor Fadilah RAJAB ${ }^{1}$, Sue Mian THEN $^{2,3}$, Yasmin Anum MOHD YUSOF ${ }^{4}$, \\ Wan Zurinah WAN NGAH ${ }^{2,4}$, Kar Yong PIN ${ }^{5}$, Mee Lee LOOI ${ }^{\$ 6}$ \\ $\left({ }^{1}\right.$ Department of Biomedical Sciences, Faculty of Allied Health, Universiti Kebangsaan Malaysia (UKM), \\ Jalan Raja Muda Abdul Aziz, 50300 Kuala Lumpur, Malaysia) \\ $\left({ }^{2}\right.$ UKM Medical Molecular Biology Institute (UMBI), Universiti Kebangsaan Malaysia (UKM), Jalan Yaacob Latiff, \\ Bandar Tun Razak, Cheras, 56000 Kuala Lumpur, Malaysia) \\ $\left({ }^{3}\right.$ School of Biomedical Science, University of Nottingham Malaysia Campus, 43500 Semenyih, Selangor, Malaysia) \\ $\left({ }^{4}\right.$ Department of Biochemistry, Faculty of Medicine, Universiti Kebangsaan Malaysia (UKM), \\ Jalan Raja Muda Abdul Aziz, 50300 Kuala Lumpur, Malaysia) \\ ( ${ }^{5}$ Forest Research Institute Malaysia (FRIM), 52109 Kuala Lumpur, Kepong, Malaysia) \\ ( ${ }^{6}$ School of Biosciences, Taylor's University, Lakeside Campus, 47500 Subang Jaya, Selangor, Malaysia) \\ †E-mail: MeeLee.Looi@taylors.edu.my \\ Received Nov. 26, 2013; Revision accepted Apr. 15, 2014; Crosschecked July 11, 2014
}

\begin{abstract}
Objective: The combination effect of Piper betle (PB) and 5-fluorouracil (5-FU) in enhancing the cytotoxic potential of 5-FU in inhibiting the growth of colon cancer cells was investigated. Methods: HT29 and HCT116 cells were subjected to 5-FU or PB treatment. 5-FU and PB were then combined and their effects on both cell lines were observed after $24 \mathrm{~h}$ of treatment. PB-5-FU interaction was elucidated by isobologram analysis. Apoptosis features of the treated cells were revealed by annexin V/PI stain. High-performance liquid chromatography (HPLC) was performed to exclude any possible chemical interaction between the compounds. Results: In the presence of PB extract, the cytotoxicity of 5-FU was observed at a lower dose $\left(\mathrm{IC}_{50} 12.5 \mu \mathrm{mol} / \mathrm{L}\right)$ and a shorter time $(24 \mathrm{~h})$ in both cell lines. Both cell lines treated with 5-FU or PB alone induced a greater apoptosis effect compared with the combination treatment. Isobologram analysis indicated that $\mathrm{PB}$ and 5-FU interacted synergistically and antagonistically in inhibiting the growth of HT29 and HCT116 cells, respectively. Conclusions: In the presence of PB, a lower dosage of 5-FU is required to achieve the maximum drug effect in inhibiting the growth of HT29 cells. However, PB did not significantly reduce 5-FU dosage in HCT116 cells. Our result showed that this interaction may not solely contribute to the apoptosis pathway.
\end{abstract}

Key words: Piperaceae, Piper betle L., 5-Fluorouracil, Isobologram analysis, Herb-drug interaction doi:10.1631/jzus.B1300303 Document code: A CLC number: R979.1

\section{Introduction}

5-Fluorouracil (5-FU) is an antimetabolite-based chemotherapeutic drug commonly used in treating

\footnotetext{
${ }^{\ddagger}$ Corresponding author

* Project supported by the Ministry of Higher Education, Malaysia (No. UKM-JJ-03-FRGS0044-2010) and Universiti Kebangsaan Malaysia (No. UKM-DPP-2014-131)

(C) Zhejiang University and Springer-Verlag Berlin Heidelberg 2014
}

solid human tumors, especially colorectal cancer. Cytotoxicity of 5-FU is attributed to its ability to inhibit thymidylate synthase activity and interrupt DNA and RNA syntheses (Kinsella et al., 1997; Noordhuis et al., 2004). However, its use is limited because of the rapid development of acquired resistance and its short half-life (Mader et al., 1998; Jin et al., 2002). Different treatment approaches have been designed to increase the efficacy of 5-FU such as optimizing the administration schedule (Pizzorno 
et al., 2009) and using a combination treatment with leucovorin and oxaliplatin (FOLFOX) (Klampfer et al., 2005). Nevertheless, drug resistance has also been noted with increasing 5-FU dosage (Mader et al., 1998; Pizzorno et al., 2009) and in combination therapy (Pizzorno et al., 2009). 5-FU resistance is conferred by the alteration in drug metabolism, drug transport mechanism, and expression of targeted proteins such as p53; as a result, cancer cells fail to undergo cell cycle arrest and apoptosis (Mader et al., 1998). p53 is the tumor-suppresser protein that helps in coordinating the response towards 5-FU treatment. About $30 \%-50 \%$ of colorectal cancer cases have been found to have mutated p53 protein and hence loss of sensitivity towards 5-FU (Mader et al., 1998; Bunz et al., 1999). Thus, there is a need for strategies to overcome drug resistance and hence enhance drug delivery to the target site of cancer.

Combination anticancer treatments using the active compounds from plant extracts are becoming a new focus of drug discovery. Natural plant extracts enriched with flavanoids, phenolic compounds, and other phytochemicals have fewer side-effects compared with chemotherapy drugs, and thus play important roles as anticancer agents (Pourcel et al., 2007). There are numerous studies (Tang et al., 2007; Wang and Yuan, 2008; Fishbein et al., 2009) showing synergistic drug-herb interactions in enhancing anticancer treatment with minimum cytotoxicity to the host cells. Fishbein et al. (2009) showed that an antiproliferative effect of Red ginsenoside enhanced 5-FU activity in human colon carcinoma, HCT116 cells. Mice treated with combined triptolide and 5-FU showed a greater tumor growth inhibition in primary tumor xenografts (Tang et al., 2007).

Piper betle (PB) is a well-known ethnomedicinal plant in the Asian region (Kumar et al., 2010). PB leaves have been known for centuries for their curative properties in, for example, preventing halitosis, and in the treatment of boils, abscesses, as well as throat and lung diseases (Guha, 2006). An active compound of $\mathrm{PB}$, hydroxychavicol (HC), has been recognized as an antioxidant, anti-proliferative, and anticancer agent (Young et al., 2006; Fathilah et al., 2010). Previous research has revealed that pretreatment of oral $\mathrm{KB}$ carcinoma cells with $\mathrm{HC}$ inhibited the attachment of KB cells to type I collagen and fibronectin, and subsequently resulted in cell cycle arrest in S and G2/M phases (Chang et al., 2002).
Chakraborty et al. (2012) showed that HC-induced reactive oxygen species (ROS)-mediated phosphorylation of c-Jun N-terminal kinase (JNK), which, in turn, phosphorylates endothelial nitric oxide synthase to produce nitric oxide and mediate cell death in chronic myeloid leukaemia without depleting glutathione levels. Chakraborty et al. (2012) also showed that multiple compounds present in crude extracts of PB may exert better anticancer effects compared with a single active compound. Combination treatment of the anticancer drug, cisplatin, with PB increased the sensitivity of liver cancer cells to cisplatin (Young et al., 2006). In this present study, we attempt to investigate the effect of $\mathrm{PB}$ on colon cancer cells and its interaction with the anticancer drug, 5-FU.

Drugs when given in combination may produce a greater or lesser effect compared with a single drug. Drug interaction occurs when the pharmacokinetics and/or pharmacodynamics of a drug is altered by the presence of another drug, food, or herbs (Hussin, 2001; Renuka et al., 2011). Pharmacodynamic interactions are usually analyzed by the isobologram, which can distinguish the additive interaction from synergistic and antagonistic interactions (Tallarida and Raffa, 1996; Chou, 2006). Synergism is achieved when either or both respective drugs require a lower concentration to reach the same effect as in the individual treatment respectively with combination index (CI) $<1$. Antagonism is defined when a higher concentration of either or both drugs achieves the same effect as the individual treatment (Chou, 2006). In this study, we found a synergistic interaction of 5-FU and PB on HT29 cells. This justified further investigation of the major active compound of PB, HC, on HT29 cells.

Apart from causing a systemic drug interaction effect, drug-drug or herb-drug interaction could reduce or enhance the bioavailability of co-administered drug (Cabrera et al., 2011). This is known as 'pharmaceutical interaction', in which two substances interact by direct chemical reaction, either before ingestion or while mixed together in the stomach and intestine (Renuka et al., 2011). For example, combination treatment of ampicillin with tannins forms an insoluble complex; this bioavailability impairment reduces the gastrointestinal absorption of ampicillin (Esimone, 2011). In our current study, we also attempt to identify any pharmaceutical interaction between PB and 5-FU. 


\section{Materials and methods}

\subsection{Aqueous extraction of $P B$ leaves}

PB leaves were collected from Bentong, Pahang, Malaysia. The fresh specimen was sent to the Botany Department Herbarium, Universiti Kebangsaan Malaysia (UKM), Bangi, Malaysia for identification. The specimen was then certified with a voucher number Herbarium UKMB-29852.

The leaves were dried and ground prior to the extraction. Extraction was conducted using a Soxhlet extractor coupled with a cooling system. The extraction method was standardized in collaboration with the Forest Research Institute of Malaysia, according to the method of Pin et al. (2011). The ratio of solvent (distilled water) to raw material was $10 \mathrm{~L} / \mathrm{kg}$ and the mixture was stirred at $60{ }^{\circ} \mathrm{C}$ for $2 \mathrm{~h}$. The aqueous extract was filtered with a muslin cloth and filter paper, and then dried in a Virtis freeze-drier (SP Scientific, USA).

\subsection{2,2-Diphenyl-1-picrylhydrazyl (DPPH) total free radical scavenging assay}

Total free radical scavenging activities of $\mathrm{PB}$ leaf aqueous extract and 4-allylpyrocatechol were determined by performing DPPH radical assay as previously described (Molyneux, 2004). Ascorbic acid (Sigma Chemical, USA) was used as a positive control. Samples were mixed with methanolic $0.5 \mathrm{mmol} / \mathrm{L}$ DPPH solution in a 1:1 ratio for $30 \mathrm{~min}$ in the dark. A total of $200 \mu \mathrm{l}$ of the reaction mixture was then transferred to a 96-well plate and the absorbance was read at $517 \mathrm{~nm}$. The scavenging activity was calculated with the equation: radical scavenging activity= [1-(absorbance of sample/absorbance of positive control) $] \times 100 \%$. The antioxidant activity of the sample is expressed as $\mathrm{IC}_{50}$, which is defined as the concentration of sample required to inhibit the formation of DPPH radicals by $50 \%$.

\subsection{Cell cultures and treatments}

Human colon cancer cell lines, HT29 and HCT116 cells (American Tissue Culture Center), were grown in complete McCoy's $5 \mathrm{~A}$ medium with L-glutamine (Invitrogen, USA). The medium was supplemented with $10 \%$ heat-inactivated $(30 \mathrm{~min}$, $56{ }^{\circ} \mathrm{C}$ ), filter-sterilized fetal bovine serum (Gibco, USA). The cells were maintained in a $37{ }^{\circ} \mathrm{C}$ humid incubator with $5 \% \mathrm{CO}_{2}$. The experiments consisted of four groups for each cell line: (1) control (cancer cells without treatment); (2) cancer cells treated with 5-FU; (3) cancer cells treated with PB leaf extract (range 100.0 to $500.0 \mu \mathrm{g} / \mathrm{ml}$ ); (4) cancer cells treated with 5-FU and PB leaf extract. HT29 cells were also treated with (1) 4-allylpyrocatechol (synthetic HC) (62.5 to $1000.0 \mu \mathrm{mol} / \mathrm{L}$ ) and (2) with 5 -FU in combination with 4-allylpyrocatechol. Serial concentrations of PB or 4-allylpyrocatechol, which gave $10 \%$ to $90 \%$ cell growth inhibition, were combined with different concentrations of 5-FU.

\subsection{Cell proliferation assay}

Cells were seeded $24 \mathrm{~h}$ prior to treatment in a 96-well plate at plating densities of 10000 cells/well in order to obtain semi-confluent culture. After respective treatments at every 12 -h interval from 12 to 72 h, 3-(4,5-dimethylthiazol-2-yl)-5-(3-carboxymethoxyphenyl)-2-(4-sulfophenyl)-2H-tetrazolium (MTS) solution $(20 \mu \mathrm{l})$ was added to each well and the plates were incubated at $37^{\circ} \mathrm{C}$ for $1 \mathrm{~h}$. MTS product was measured at absorbance $490 \mathrm{~nm}$ and cell viability was calculated using the equation: cell viability $=$ (absorbance of sample/absorbance of control) $\times 100 \%$.

\subsection{Combination index (CI) analysis}

Drug combination effect was determined by the Chou and Talalay equation (Chou, 2006): $\mathrm{CI}=\left(d_{\mathrm{A}} / D_{\mathrm{A}}\right)+$ $\left(d_{\mathrm{B}} / D_{\mathrm{B}}\right) . d_{\mathrm{A}}$ and $d_{\mathrm{B}}$ are the doses of individual drugs alone, i.e., the concentration of 5-FU or $\mathrm{PB} /$ 4-allylpyrocatechol, respectively, that gives $50 \%$ inhibition. $D_{\mathrm{A}}$ and $D_{\mathrm{B}}$ are the doses of 5-FU and PB/ 4-allylpyrocatechol in combination that inhibits 50\% of cell growth. $\mathrm{CI}>1, \mathrm{CI}=1$, and $\mathrm{CI}<1$ indicate antagonistic, additive, and synergistic effects, respectively.

\subsection{Cell apoptosis analysis}

Control and treated cancer cells were trypsinized and cell pellets collected. Pellets were resuspended in $100 \mu \mathrm{l}$ of $1 \times$ annexin binding buffer $(100 \mathrm{mmol} / \mathrm{L}$ 2-[4-(2-hydroxyethyl)-1-piperazinyl] ethanesulfonic acid (HEPES), pH 7.5, $1.4 \mathrm{~mol} / \mathrm{L} \mathrm{NaCl}$, and $25 \mathrm{mmol} / \mathrm{L}$ $\mathrm{CaCl}_{2}$ ). Five microlitres of annexin $\mathrm{V}$ conjugates (Invitrogen, USA) and $1 \mu \mathrm{l}$ of $100 \mu \mathrm{g} / \mathrm{ml}$ propidium iodide (Sigma, USA) were then added to the mixture and incubated at room temperature for $15 \mathrm{~min}$. At the end of incubation, $400 \mu \mathrm{l}$ of annexin binding buffer was added and the cells were analyzed within $1 \mathrm{~h}$ using a Facs Arial II flow cytometer (BD Biosciences, Canada). 


\subsection{High-performance liquid chromatography (HPLC) analysis}

HPLC analysis was performed on a Prominence LC (Shimadzu Scientific Intruments, Japan) coupled with SPD-20A/20AV, UV-VIS detector. A C18 100A column $(250 \mathrm{~mm} \times 4.6 \mathrm{~mm}, 5 \mu \mathrm{m}$ particle size $)$ was used as stationary phase. Elution was performed using a gradient that consisted of a mixture of $0.1 \%$ orthophosphoric acid in Milli-Q water and $100 \%$ acetonitrile, in accordance with the method of Pin et al. (2011) The flow rate of the mobile phase was $1 \mathrm{ml} / \mathrm{min}$ at room temperature. Chromatograms were acquired at 200 and $260 \mathrm{~nm}$ for the detection of $\mathrm{PB} / 4$-allylpyrocatechol and 5-FU, respectively (Ahmad et al., 2011; Pin et al., 2011).

\section{Results}

A higher concentration $(200.0 \mu \mathrm{g} / \mathrm{ml})$ of PB extract was needed to reduce DPPH radicals by $50 \%$ compared with ascorbic acid $(60.0 \mu \mathrm{g} / \mathrm{ml})$.

The $\mathrm{IC}_{50}$ values of 5-FU-treated HT29 and HCT116 cells were 130.0 and $12.5 \mu \mathrm{mol} / \mathrm{L}$, respectively, at $72 \mathrm{~h}$. The $\mathrm{IC}_{50}$ values of PB-treated HT29 and HCT116 cells were 200.0 and $187.5 \mu \mathrm{g} / \mathrm{ml}$, respectively, after $36 \mathrm{~h}$ of treatment. HT29 cells treated with 4-allylpyrocatechol showed a lower $\mathrm{IC}_{50}$ $(15.0 \mu \mathrm{g} / \mathrm{ml})$ after $24 \mathrm{~h}$ of treatment. In the presence of PB extract or 4-allylpyrocatechol, the cytotoxic effect of 5-FU against HT29 cells was observed at a lower dose $(<12.5 \mu \mathrm{mol} / \mathrm{L})$ and at a shorter time $(24 \mathrm{~h})$ (Figs. 1a-1c). HT29 and HCT116 cells treated with 5-FU and PB alone induced greater apoptosis effects compared with the combination treatment (Figs. $2 \mathrm{a}$ and $2 \mathrm{~b}$ ).

$\mathrm{CI}$ analysis indicated $\mathrm{PB}$ and 5-FU interacted synergistically (as shown by $\mathrm{CI}<1$ ) in HT29 cells, but antagonistically in HCT116 cells (CI>1) (Fig. 3a). Combination treatment of 4-allylpyrocatechol and 5-FU interacted antagonistically in HT29 cells (Fig. 3b).

Interaction of 5-FU and $\mathrm{PB} / 4$-allylpyrocatechol was evaluated by HPLC. Retention time of PB and 5-FU was observed at $4.0 \mathrm{~min}(200 \mathrm{~nm})$ and $3.0 \mathrm{~min}$ $(260 \mathrm{~nm})$, respectively, with a noticeable shift of peak-height as the concentration varied. The mixture was analyzed at 200 and $260 \mathrm{~nm}$, respectively. Peak intensities of 5-FU and $\mathrm{PB} / 4$-allylpyrocatechol from the mixture were the same as when they were analyzed individually. The mixture of 5-FU and $\mathrm{PB} /$ 4-allylpyrocatechol did not show additional compounds by HPLC separation.
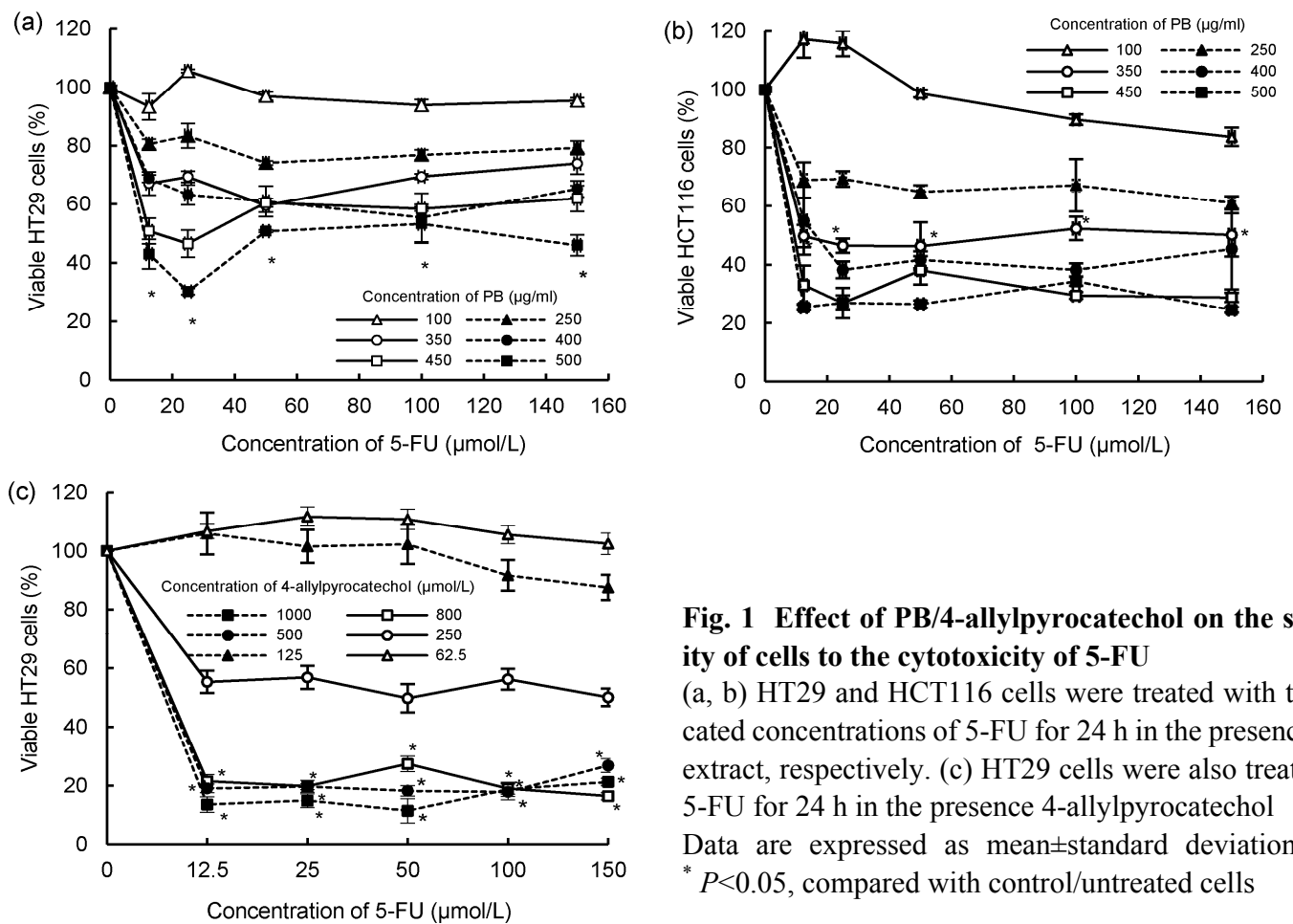

Fig. 1 Effect of PB/4-allylpyrocatechol on the sensitivity of cells to the cytotoxicity of 5-FU

(a, b) HT29 and HCT116 cells were treated with the indicated concentrations of 5-FU for $24 \mathrm{~h}$ in the presence of $\mathrm{PB}$ extract, respectively. (c) HT29 cells were also treated with 5 -FU for $24 \mathrm{~h}$ in the presence 4-allylpyrocatechol Data are expressed as mean \pm standard deviation $(n=3)$. ${ }^{*} P<0.05$, compared with control/untreated cells 
(a)
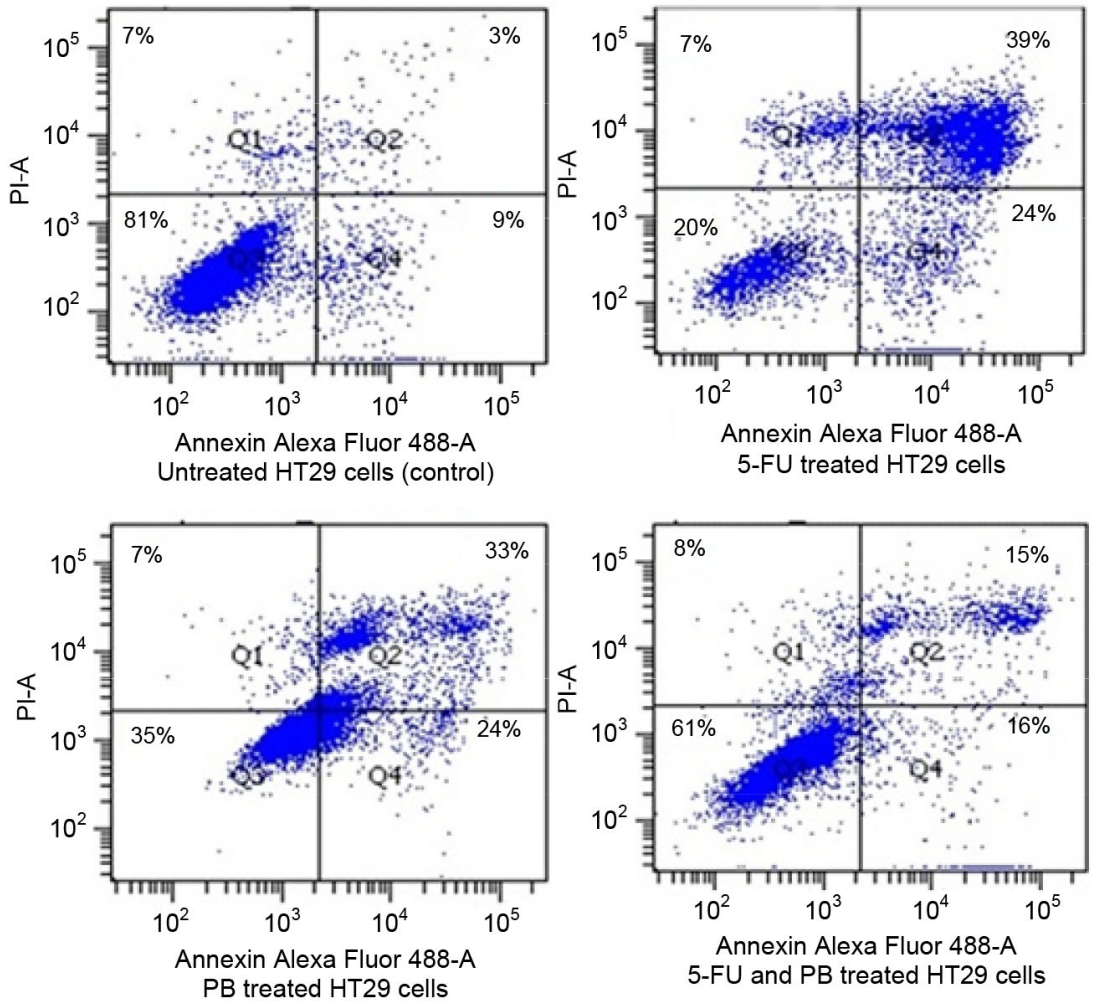

(b)
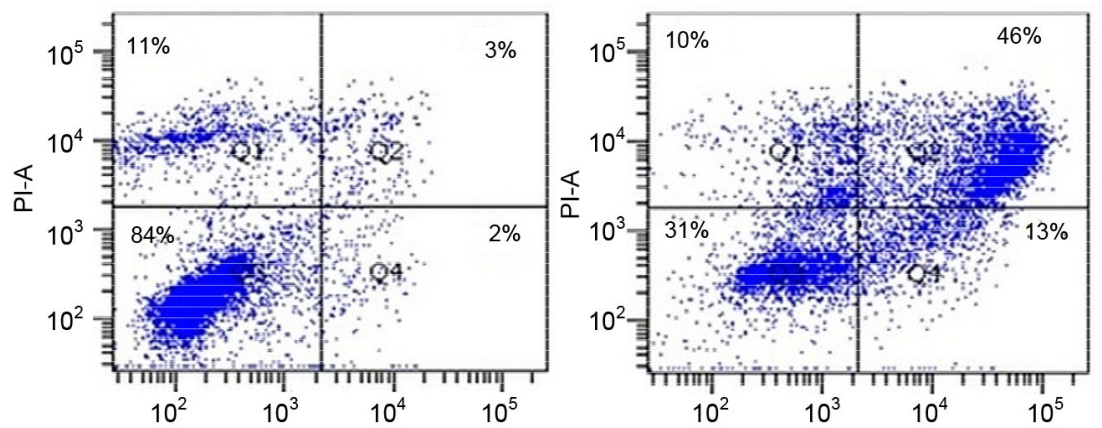

Annexin Alexa Fluor 488-A Untreated HCT116 cells (control)

Annexin Alexa Fluor 488-A

5-FU treated HCT116 cells
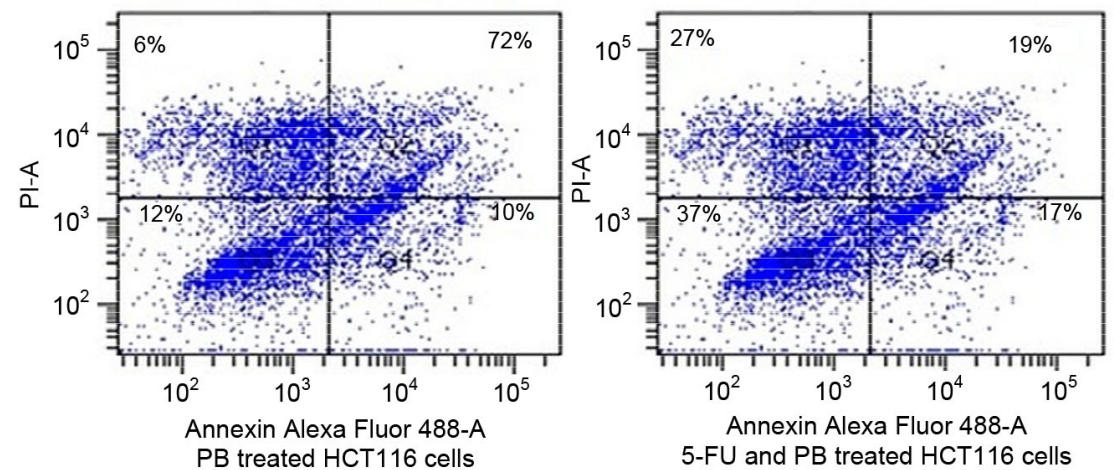

Fig. 2 Apoptosis assessment of PB and 5-FU either in combination or alone in HT29 (a) and HCT116 (b) cells Annexin V-positive/PI negative cells are in early stages of apoptosis and double positive cells are in late stages of apoptosis. Annexin V-negative/PI positive cells are necrotic 

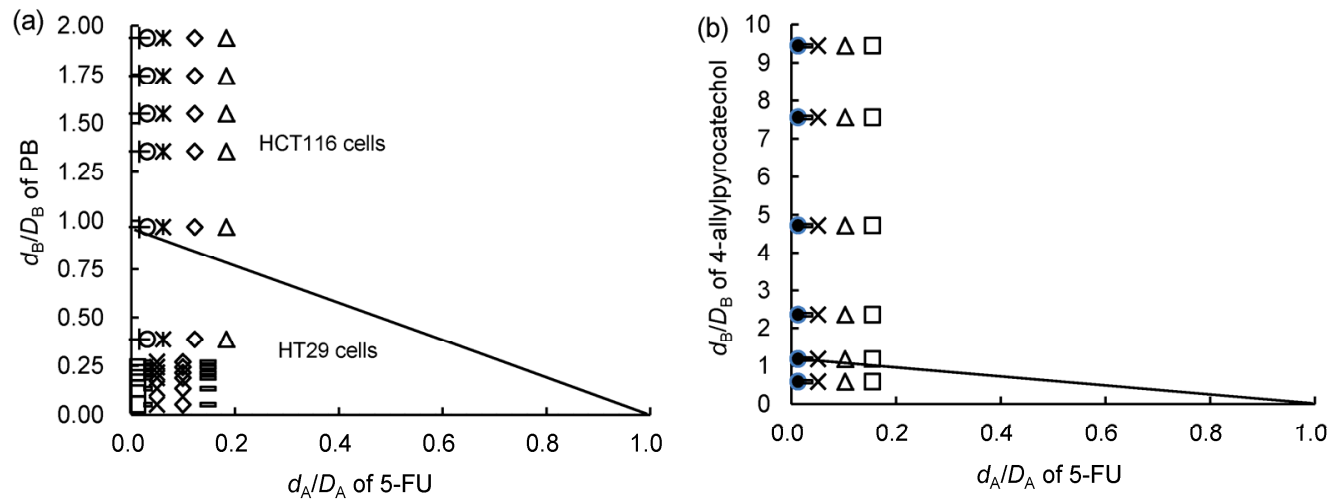

Fig. 3 Isobologram at 50\% effect level of simultaneous exposure of HT29 and HCT116 cells to 5-FU and PB/ 4-allylpyrocatechol

The solid line $(\mathrm{CI}=1)$ indicates the alignment of theoretical values of an additive interaction between two substances. Values above the solid line represent antagonistic interaction; values below the line represent synergism. (a) Concurrent $24 \mathrm{~h}$ exposure of HT29 cells and HCT116 cells to 5-FU and PB exhibits synergistic and antagonistic treatment effect respectively. (b) Simultaneous treatment of 5-FU and 4-allylpyrocatechol treatment inhibits HT29 cell growth antagonistically

\section{Discussion}

In this study, we utilized two different colon cancer cell lines, i.e., HT29 and HCT116, each with specific characteristics, to test whether these cancer cells were resistant to the treatment of PB leaf extract and the chemotherapy drug 5-FU alone and whether the combination therapy would enhance the inhibitory effect of 5-FU. HT29 and HCT116 cells have different gene profiles. HT29 cells are known to have the mutated tumor-suppressor gene, $p 53$. This is a determinant factor for the success of 5-FU treatment (Bunz et al., 1999). Our results showed that HCT116 cells with a functional $p 53$ are more sensitive to 5 -FU than HT29 cells. Lack of functional p53 protein in HT29 cells leads to reduced expression of pro-apoptosis protein, which then renders the cells resistant to apoptosis (Boyer et al., 2004). Thus, higher dosage of 5-FU was needed to induce cell death in HT29 cells.

Previous studies suggested that combination treatment is more effective in treating cancer; it targets different mechanisms and reduces the chances of developing resistance (Hiss et al., 2007; Felth et al., 2009; Majumdar et al., 2009; Tong et al., 2011; Hörmann et al., 2012; Kumar et al., 2012; Slovin, 2012). Tunicamycin is an antibiotic which can reduce the effective dosage of doxorubicin, epirubicin, vincristine, and cis-diamine dichloroplatinum in multiresistant UWOV2 ovarian cancer cells, thus enhancing their cytotoxic effect (Hiss et al., 2007). Majumdar et al. (2009) found the combination of curcumin and resveratrol was effective in inhibiting the growth of colon cancer cells. Low doses of genistein from soybean increased the sensitivity of prostate cancer initiating cells to drugs such as docetaxel and cyclopamine (Hörmann et al., 2012; Kumar et al., 2012). Earlier studies showed that 5-FU interacts synergistically with either triptolide or dichloroacetate in killing HT29 cells (Tang et al., 2007; Tong et al., 2011). Combination treatment of 5-FU with dichloroacetate enhanced the 5-FU cytotoxicity at reducing 5-FU concentration from 798.4 to $80.0 \mu \mathrm{mol} / \mathrm{L}$ (Tang et al., 2007). PB exhibited potent anticancer properties (Pin et al., 2010), but it is seldom tested in the combination treatment. Here, we investigated its combination treatment effect with 5-FU in colorectal cancer cells.

In our study, PB extract enhanced the cytotoxicity of 5-FU by reducing its dosage and treatment time in HT29 cells (Fig. 1a). However, combination treatment did not show an obvious apoptosis hallmark in HT29 cells. Therefore, the cell death observed in the combination treatment group is unlikely to be triggered by the apoptosis pathway and we suggest that PB causes cell death by mediating cell cycle arrest. On the other hand, we observed that the combination of 5-FU and $\mathrm{PB}$ did not mitigate the 5-FU dosage in HCT116 cells, but necrosis was prominent 
when HCT116 cells were treated by combination. This may be due to the excessive cytotoxic induction by the treatment, which leads to early massive apoptosis followed by failure of complete phagocytosis as previously described (Zong and Thompson, 2006).

The synergistic interaction of 5-FU and $\mathrm{PB}$ on HT29 cells justified further investigation of the major active compound of $\mathrm{PB}, \mathrm{HC}$, on HT29 cells. HC is a major phenolic compound found in $\mathrm{PB}$ leaves (Hemamalini et al., 2012). The presence of two hydroxyl $(\mathrm{OH})$ groups in $\mathrm{HC}$ increases the antioxidant and anticancer properties of PB (Pin et al., 2010). Our DPPH result revealed that PB at a concentration of $250 \mu \mathrm{g} / \mathrm{ml}$ had the highest scavenging activity while $\mathrm{HC}$ showed lower scavenging activity compared with the crude PB extract. The potent antioxidant capacity exhibited by the crude PB extract may be due to the presence of other phenolic compounds such as vitamins $\mathrm{C}$ and $\mathrm{E}$ (Hemamalini et al., 2012). Our study demonstrated the potential anticancer effects of $\mathrm{PB}$ and $\mathrm{HC}$ since they exerted a cytotoxic effect in both colorectal cancer cells at concentrations of more than $100 \mu \mathrm{g} / \mathrm{ml}$. The cytotoxic effect of HC was through the formation of electrophilic metabolites - quinone, quinone methide, and imine methide - via the oxidative metabolism of HC (Chang et al., 2002; Jeng et al., 2002). The formation of electrophile metabolite conjugates with the reduced glutathione and reduced glutathione content sensitized the cells towards ROS (Nakagawa et al., 2009). Our results showed that 4-allylpyrocatechol (synthetic HC) is more potent compared with the crude PB extract in killing HT29 cells. However, combination treatment of 4-allylpyrocatechol and 5-FU on HT29 cells showed an antagonistic interaction. This observation suggests that the synergistic effect of PB extract and 5-FU on HT29 cells may not solely be due to its major active compound, $\mathrm{HC}$, since PB extract also contains other phytochemicals such as chavibetol, chavicol, eugenol, and ursolic acid, which may be involved in mediating apoptosis in cancer cells (Chang et al., 2002; Jeng et al., 2004; Arambewela et al., 2006; Young et al., 2006; Yamai et al., 2009). These other bioactive compounds may be present and may have triggered the synergistic effect observed in our current study. Our finding is in accordance with the study of Young et al. (2006), who found that the crude extract of PB exhibited a stronger cytotoxicity than the bioactive compounds, $\mathrm{HC}$ and eugenol, when acting in combination with cisplatin.

Incompatibility interaction is an undesired reaction that occurs between a drug and another drug or solution (Newton, 2009). There are two types of incompatibility interaction. Physical reaction usually refers to either phase separation or precipitation due to a change of relation between ionization, nonionization, and solubility (Newton, 2009). In chemical incompatibility, drugs are chemically degraded and can manifest themselves through turbidity, precipitation, and color change. Chemical incompatibility can probably be identified with HPLC (Newton, 2009; Cabrera et al., 2011). In our study, a simple visual examination of the 5-FU and PB mixture did not show the presence of any precipitation in solution, suggesting that the interaction of 5-FU/PB and 5-FU/ 4-allylpyrocatechol is physically compatible. Based on our HPLC results, no additional compound was resolved from the 5-FU and $\mathrm{PB} / 4$-allylpyrocatechol mixture, indicating that there is a compatible and stable interaction between 5-FU and $\mathrm{PB} / 4$-allylpyrocatechol prior to treatment of the cells.

In conclusion, 4-allylpyrocatechol and $\mathrm{PB}$ crude extract have significantly mitigated the 5-FU dosage and enhanced the cytotoxicity of the drug in killing colon cancer cells. However, CI and apoptosis analysis revealed that PB crude extract and 4-allylpyrocatechol may exert their cytotoxicity via different mechanisms other than apoptosis when treated together with 5-FU. An antagonistic interaction of 5-FU and 4-allylpyrocatechol suggests that 4-allylpyrocatechol may not be the only compound responsible for enhancing the 5-FU effect, and there may be other bioactive compounds in $\mathrm{PB}$ capable of modulating the cytotoxic effect of 5-FU.

\section{Acknowledgements}

We gratefully acknowledge Miss Nor Syahida ALIAHMAT, from Department of Biochemistry, UKM, Malaysia, for her help in the PB leaf collection.

\section{Compliance with ethics guidelines}

Pek Leng NG, Nor Fadilah RAJAB, Sue Mian THEN, Yasmin Anum MOHD YUSOF, Wan Zurinah WAN NGAH, Kar Yong PIN, and Mee Lee LOOI declare that they have no conflict of interest.

This article does not contain any studies with human or animal subjects performed by any of the authors. 


\section{References}

Ahmad, M., Usman, M., Madni, A., et al., 2011. A fast and simple HPLC-UV method for simultaneous determination of three anti-cancer agents in plasma of breast cancer patients and its application to clinical pharmacokinetics. Afr. J. Pharm. Pharmacol., 5(7):915-922.

Arambewela, L., Arawwawala, M., Rajapaksa, D., 2006. Piper betle: a potential natural antioxidant. Int. J. Food Sci. Technol., 41(s1):10-14. [doi:10.1111/j.1365-2621.2006. 01227.x]

Boyer, J., McLean, E.G., Aroori, S., et al., 2004. Characterization of p53 wild-type and null isogenic colorectal cancer cell lines resistant to 5-fluorouracil, oxaliplatin, and irinotecan. Clin. Cancer Res., 10(6):2158-2167. [doi:10. 1158/1078-0432.CCR-03-0362]

Bunz, F., Hwang, P.M., Torrance, C., et al., 1999. Disruption of p53 in human cancer cells alters the responses to therapeutic agents. J. Clin. Invest., 104(3):263-269. [doi:10. 1172/JCI6863]

Cabrera, J., Mancuso, M., Cabrera-Franquiz, F., et al., 2011. Stability and compatibility of the mixture of tramadol, ketorolac, metoclopramide and ranitidine in a solution for intravenous perfusion. Farm. Hosp., 35(2):80-83 (in Spanish). [doi:10.1016/j.farma.2010.01.007]

Chakraborty, J.B., Mahato, S.K., Joshi, K., et al., 2012. Hydroxychavicol, a Piper betle leaf component, induces apoptosis of CML cells through mitochondrial reactive oxygen species-dependent JNK and endothelial nitric oxide synthase activation and overrides imatinib resistance. Cancer Sci., 103(1):88-99. [doi:10.1111/j.1349-7006. 2011.02107.x]

Chang, M., Uang, B., Wu, H.L., et al., 2002. Inducing the cell cycle arrest and apoptosis of oral KB carcinoma cells by hydroxychavicol: roles of glutathione and reactive oxygen species. Brit. J. Pharmacol., 135(3):619-630. [doi:10. 1038/sj.bjp.0704492]

Chou, T.C., 2006. Theoretical basis, experimental design, and computerized simulation of synergism and antagonism in drug combination studies. Pharmacol. Rev., 58(3):621-681. [doi:10.1124/pr.58.3.10]

Esimone, C.O., 2011. Drug-drug and herb-drug interactiona comment. J. Res. Nat. Dev., 9(1):47-59.

Fathilah, A.R., Sujata, R., Norhanom, A.W., et al., 2010. Antiproliferative activity of aqueous extract of Piper betle L. and Psidium guajava L. on KB and HeLa cell lines. J. Med. Plants Res., 4(11):987-990.

Felth, J., Rickardson, L., Rosen, J., et al., 2009. Cytotoxic effects of cardiac glycosides in colon cancer cells, alone and in combination with standard chemotherapeutic drugs J. Nat. Prod., 72(11):1969-1974. [doi:10.1021/np900210m]

Fishbein, A.B., Wang, C.Z., Li, X.L., et al., 2009. Asian ginseng enhances the anti-proliferative effect of 5-fluorouracil on human colorectal cancer: comparison between white and red ginseng. Arch. Pharm. Res., 32(4):505-513. [doi:10.1007/s12272-009-1405-9]

Guha, P., 2006. Betel leaf: the neglected green gold of India. $J$.
Hum. Ecol., 19(2):87-93.

Hemamalini, V., Dass Prakash, M.V., Sivaramakrishnan, S., 2012. Evaluation of the in vitro antioxidant, antienteropathogenic and anticancer efficacy of natural and synthetic hydroxychavicol. Int. J. Medicobiol. Res., 1(5): 250-254.

Hiss, D.C., Gabriels, G.A., Folb, P.I., 2007. Combination of tunicamycin with anticancer drugs synergistically enhances their toxicity in multidrug-resistant human ovarian cystadenocarcinoma cells. Cancer Cell Int., 7(1):5. [doi:10. 1186/1475-2867-7-5]

Hörmann, V., Kumi-Diaka, J., Durity, M., et al., 2012. Anticancer activities of genistein-topotecan combination in prostate cancer cells. J. Cell. Mol. Med., 16(11):26312636. [doi:10.1111/j.1582-4934.2012.01576.x]

Hussin, A.H., 2001. Adverse effects of herbs and drug-herbal interactions. Malays. J. Pharm., 1(2):39-44.

Jeng, J., Chen, S., Liao, C., et al., 2002. Modulation of platelet aggregation by areca nut and betel leaf ingredients: roles of reactive oxygen species and cyclooxygenase. Free Radic. Biol. Med., 32(9):860-871. [doi:10.1016/S08915849(02)00749-9]

Jeng, J.H., Wang, Y.J., Chang, W.H., et al., 2004. Reactive oxygen species are crucial for hydroxychavicol toxicity toward KB epithelial cells. Cell. Mol. Life Sci., 61(1): 83-96. [doi:10.1007/s00018-003-3272-8]

Jin, J., Huang, M., Wei, H.L., et al., 2002. Mechanism of 5-fluorouracil required resistance in human hepatocellular carcinoma cell line $\mathrm{Bel}_{7402}$. World J. Gastroenterol., 8(6):1029-1034.

Kinsella, A., Smith, D., Pickard, M., 1997. Resistance to chemotherapeutic antimetabolites: a function of salvage pathway involvement and cellular response to DNA damage. Brit. J. Cancer, 75(7):935-945. [doi:10.1038/ bjc.1997.164]

Klampfer, L., Swaby, L.A., Huang, J., et al., 2005. Oncogenic Ras increases sensitivity of colon cancer cells to 5-FUinduced apoptosis. Oncogene, 24(24):3932-3941. [doi:10. 1038/sj.onc.1208552]

Kumar, N., Misra, P., Dube, A., et al., 2010. Piper betle Linn. a maligned Pan-asiatic plant with an array of pharmacological activities and prospects for drug discovery. Curr. Sci., 99(7):922-932.

Kumar, S., Choudhary, S., Singh, N., et al., 2012. Combination of natural drugs: an emerging trend in cancer chemotherapy. J. Drug Deliv. Ther., 2(3):97-105.

Mader, R.M., Müller, M., Steger, G.G., 1998. Resistance to 5-fluorouracil. Gen. Pharmacol., 31(5):661-666. [doi:10. 1016/S0306-3623(98)00191-8]

Majumdar, A.P., Banerjee, S., Nautiyal, J., et al., 2009. Curcumin synergizes with resveratrol to inhibit colon cancer. Nutr. Cancer, 61(4):544-553. [doi:10.1080/0163558090 2752262]

Molyneux, P., 2004. The use of the stable free radical diphenylpicrylhydrazyl (DPPH) for estimating antioxidant activity. Songklanakarin J. Sci. Technol., 26(2):211-219. 
Nakagawa, Y., Suzuki, T., Nakajima, K., et al., 2009. Biotransformation and cytotoxic effects of hydroxychavicol, an intermediate of safrole metabolism, in isolated rat hepatocytes. Chem. Biol. Interact., 180(1):89-97. [doi:10. 1016/j.cbi.2009.02.003]

Newton, D.W., 2009. Drug incompatibility chemistry. Am. J. Health Syst. Pharm., 66(4):348-357. [doi:10.2146/ajhp08 0059]

Noordhuis, P., Holwerda, U., van der Wilt, C., et al., 2004. 5-Fluorouracil incorporation into RNA and DNA in relation to thymidylate synthase inhibition of human colorectal cancers. Ann. Oncol., 15(7):1025-1032. [doi:10. 1093/annonc/mdh264]

Pin, K., Chuah, A.L., Rashid, A.A., et al., 2010. Antioxidant and anti-inflammatory activities of extracts of betel leaves (Piper betle) from solvents with different polarities. $J$. Trop. For. Sci., 22(4):448-455.

Pin, K.Y., Ilicali, C., Luqman Chuah, A., et al., 2011. Modelling of freezing kinetics of extract of betel leaves (Piper betle L.). Int. J. Food Eng., 7(1):Art. 15. [doi:10.2202/15563758.1692]

Pizzorno, G., Diasio, R.B., Cheng, Y.C., 2009. Cancer Medicine. People's Medical Publishing House-USE, USA.

Pourcel, L., Routaboul, J.M., Cheynier, V., et al., 2007. Flavonoid oxidation in plants: from biochemical properties to physiological function. Trends Plant Sci., 12(1):29-36. [doi:10.1016/j.tplants.2006.11.006]

Renuka, G., Thiruvengadarajan, V.S., Amruthkumar, N., et al., 2011. A review on herb-drug interactions. Int. J. Pharm. Res. Dev., 3(3):136-153.
Slovin, S., 2012. Chemotherapy and immunotherapy combination in advanced prostate cancer. Clin. Adv. Hematol. Oncol., 10(2):90-100.

Tallarida, R.J., Raffa, R.B., 1996. Testing for synergism over a range of fixed ratio drug combinations: replacing the isobologram. Life Sci., 58(2):23-28. [doi:10.1016/00243205(95)02271-6]

Tang, X.Y., Zhu, Y.Q., Tao, W.H., et al., 2007. Synergistic effect of triptolide combined with 5-fluorouracil on colon carcinoma. Postgrad. Med. J., 83(979):338-343. [doi:10. 1136/pgmj.2006.055426]

Tong, J., Xie, G., He, J., et al., 2011. Synergistic antitumor effect of dichloroacetate in combination with 5-fluorouracil in colorectal cancer. J. Biomed. Biotechnol., 2011:740564. [doi:10.1155/2011/740564]

Wang, C.Z., Yuan, C.S., 2008. Potential role of ginseng in the treatment of colorectal cancer. Am. J. Chin. Med., 36(6): 1019-1028. [doi:10.1142/S0192415X08006545]

Yamai, H., Sawada, N., Yoshida, T., et al., 2009. Triterpenes augment the inhibitory effects of anticancer drugs on growth of human esophageal carcinoma cells in vitro and suppress experimental metastasis in vivo. Int. J. Cancer, 125(4):952-960. [doi:10.1002/ijc.24433]

Young, S.C., Wang, C.J., Hsu, J.D., et al., 2006. Increased sensitivity of HepG2 cells toward the cytotoxicity of cisplatin by the treatment of Piper betel leaf extract. Arch. Toxicol., 80(6):319-327. [doi:10.1007/s00204-005-0051-3]

Zong, W.X., Thompson, C.B., 2006. Necrotic death as a cell fate. Genes Dev., 20(1):1-15. [doi:10.1101/gad.1376506]

\section{中文概要:}

\section{本文题目：蒌叶提取物增强 5-氟尿嘧啶对结肠癌细胞 HT29 和 HCT116 的生长抑制作用}

Piper betle leaf extract enhances the cytotoxicity effect of 5-fluorouracil in inhibiting the growth of HT29 and HCT116 colon cancer cells

研究目的：探讨蒌叶 (PB) 提取物对 5-氟尿嘧啶 (5-FU) 抑制结肠癌细胞 HT29 和 HCT116 生长的影响。

研究方法: HT29 和 HCT116 细胞分别给予 PB、5-FU 以及两种药物联合治疗 24 小时, 应用等效线图法 分析 PB 和 5-FU 的药效学相互作用, Annexin V/PI 染色法检测 HT29 和 HCT116 细胞的调亡 情况，高效液相色谱法排除 PB 和 5-FU 间任何可能的相互化学作用。

重要结论: 联合 PB, 低剂量 5-FU 可以在短时间内起到细胞毒作用, 而单独应用 PB 或 5-FU 治疗较联合 治疗可以诱导更多细胞发生调亡。进一步采用等效线图法分析显示 PB 和 5-FU 的联合作用在 抑制结肠癌细胞 HT29 和 HCT116 的生长中分别体现出协同和拮抗作用。因此可以认为在 HT29 细胞中, PB 使得较低剂量 5-FU 发挥最大抑制结肠癌细胞生长效果, 然而在 HCT116 细 胞中, PB 没有显著降低 5-FU 的药物浓度, 说明 PB 和 5-FU 的相互作用不仅仅体现在诱导细 胞凋亡方面。

关键词组：胡椒科；萎叶；5-氟尿嘧啶；等效线图法；草药-药物相互作用 